\title{
Enhanced Degradation of TNT and RDX by Bio-reduced Iron Bearing Soil Minerals
}

\author{
Changhyun Cho, Sungjun Bae and Woojin Lee* \\ Department of Civil and Environmental Engineering, Korea Advanced Institute of Science and Technology, \\ 291 Daehak-ro, Yuseong-gu, Daejeon 305-701, Republic of Korea
}

(Received March 15, 2012, Revised March 25, 2012, Accepted March 26, 2012)

\begin{abstract}
We demonstrated that reductive degradation of 2,4,6-Trinitrotoluene (TNT) and hexahydro1,3,5-trinitro-1,3,5-triazine (Royal Demolition Explosive, RDX) can be enhanced by bio-reduced ironbearing soil minerals (IBSMs) using Shewanella putrefaciens CN32 (CN32). The degradation kinetic rate constant of TNT by bio-reduced magnetite was the highest $\left(0.0039 \mathrm{~h}^{-1}\right)$, followed by green rust $\left(0.0022 \mathrm{~h}^{-1}\right)$, goethite $\left(0.0017 \mathrm{~h}^{-1}\right)$, lepidocrocite $\left(0.0016 \mathrm{~h}^{-1}\right)$, and hematite $\left(0.0006 \mathrm{~h}^{-1}\right)$. The highest rate constant was obtained by bio-reduced lepidocrocite $\left(0.1811 \mathrm{~h}^{-1}\right)$ during RDX degradation, followed by magnetite $\left(0.1700 \mathrm{~h}^{-1}\right)$, green rust $\left(0.0757 \mathrm{~h}^{-1}\right)$, hematite $\left(0.0495 \mathrm{~h}^{-1}\right)$, and goethite $\left(0.0394 \mathrm{~h}^{-1}\right)$. Significant increase of Fe(II) was observed during the reductive degradation of TNT and RDX by bio-reduced IBSMs. X-ray diffraction and electron microscope analyses were conducted for identification of degradation mechanism of TNT and RDX in this study. 4-amino-dinitrotoluene were detected as products during TNT degradation, while Hexahydro-1nitroso-3,5-dinitro-1,3,5-triazine, Hexahydro-1,3-dinitroso-5-nitro-1,3,5triazine, and Hexahydro-1,3,5trinitroso-1,3,5-triazine were observed during RDX degradation.
\end{abstract}

Keywords: 2,4,6-Trinitrotoluene (TNT); hexahydro-1,3,5-trinitro-1,3,5-triazine (RDX); iron-bearing soil minerals; Shewanella putrefaciens CN32

\section{Introduction}

The cyclic nitramine explosives compounds are highly energetic chemicals that rapidly release large amounts of gaseous products and energy upon detonation (Lotufo et al. 2009). Because of their explosive properties, these chemicals are extensively used in the military, construction site, and mining industry. Due to intensive use of explosives as described above, the contamination of soil and groundwater by these has been continuously reported, especially in the proximity of munitions manufacturing plants (Hundal et al. 1997a, Boopathy and Manning 2000). Among them, 2,4,6Trinitrotoluene (TNT) and hexahydro-1,3,5-trinitro-1,3,5-triazine (Royal Demolition Explosive, RDX) are the most widely used explosives all over the world. (Spain et al. 2000). TNT has been known to be carcinogenic and mutagenic and is acutely toxic to microbes, algae, fish, and other organisms (Spain et al. 2000). RDX, heterocyclic nitramine, is a persistent compound that can threaten human

*Corresponding author, Professor, E-mail: woojin_lee@kaist.ac.kr 
health due to its toxicity (Yinon 1990).

Because of their toxicity, many efforts have been made to effectively degrade TNT and RDX to date. The reductive degradation of TNT by photocatalytic reaction (Schmelling et al. 1996), CO dehydrogenase (Huang et al. 2000), zero valent iron (Hundal et al. 1997b) have been reported. The reductive degradation of RDX by chemical reductants such as zero-valent iron (Singh et al. 1998, Naja et al. 2008), freshly precipitated iron minerals in aqueous Fe(II) solution (Boparai et al. 2010), and iron organic ligand complexes (Kim and Strathmann 2007) have shown successful degradation of RDX. Bioreduction of TNT and RDX using microorganism can be a great alternative for degradation of explosives in sediment or soil (Boopathy and Kulpa 1992, Adrian and Arnett 2004, Sherburne et al. 2005, Thompson et al. 2005, Meyers et al. 2007). It has been also reported that RDX degradation was greatly enhanced in anaerobic condition due to the initial nitro $\rightarrow$ nitroso degradation pathway (Adrian et al. 2003).

Degradation of various organic contaminants (e.g., chlorinated compounds and explosives) by iron-bearing soil minerals (IBSMs) has been reported in everywhere (Lee and Batchelor 2002a, b, Gregory et al. 2004, Larese-Casanovva and Scherer 2008, Oh et al. 2008). However, the IBSMs can be lost their reactivity after the reductive degradation of explosives due to the oxidation of Fe(II) to $\mathrm{Fe}(\mathrm{III})$ on their surfaces. The reduction potential of the IBSMs was decreased and the reductive degradation of the explosives was inhibited. Therefore, it is very important to recover the reactivity of the IBSMs for further reductive degradation reaction.

Bioreduction of IBSM by dissimilatory iron-reducing bacteria (DIRB) can be a great option to recover the reactivity of IBSMs. (Perez-Gonzalez et al. 2010, Maithreepala and Doong 2009, Fredrickson et al. 1998, O'Loughlin 2008, Zachara et al. 1998). However, there is lack of knowledge on the recovery of IBSM reactivities by DIRB for the reductive degradation of explosives to date. Thus, it is timely to investigate the possibility for the enhanced degradation of explosives by bioreduced IBSMs.

The objectives of this study were to investigate the enhanced degradation of TNT and RDX by bio-reduced IBSMs, to find out the transformation products of TNT and RDX and propose the each reaction mechanism.

\section{Materials and methods}

\subsection{Chemicals}

Chemicals used in the experiment were TNT (Accustandard), RDX (Accustandard), sodium DLlactate (Sigma), dipotassium phosphate $\left(\mathrm{K}_{2} \mathrm{HPO}_{4}\right)$ (Junsei, Japan), monopotassium phosphate $\left(\mathrm{KH}_{2} \mathrm{PO}_{4}\right)$ (Sigma), anthraquinone-2-sulfonic (AQS) (Sigma). Methanol (Merck) and acetonitrile (J.T.Baker) for preparation of TNT, RDX stock solution were all HPLC grade. 1,4-piperazinediehanesulfonic acid (PIPES) was used for buffered medium in all experiments. Deaerated deionized water (DDW, $18 \mathrm{M} \Omega \cdot \mathrm{cm}$ ) was prepared by using ultra pure water from ELGA PURELAB Classic system and purging it by $\mathrm{N}_{2}$ for $4 \mathrm{~h}$ and stored in an anaerobic chamber filled with $95 \% \mathrm{~N}_{2}$ and $5 \% \mathrm{H}_{2}$ (Coy Laboratory Products Inc.). Unless stated otherwise, all experiments were prepared by using DDW purged by $\mathrm{N}_{2}$ and conducted in an anaerobic chamber. 


\subsection{Preparation of IBSMs}

Magnetite $\left(\mathrm{Fe}^{\mathrm{II}}{ }_{1}{ }_{1}{ }_{2} \mathrm{O}_{4}\right)$ and green rust $\left(\mathrm{GR}-\mathrm{SO}_{4}\right)$ were synthesized by following the procedure previously described (Bae and Lee 2010, Srinivasan et al. 1996). It was washed two times using $\mathrm{DDW}$, freeze-dried, and stored in the anaerobic chamber. Lepidocrocite $\left(\gamma-\mathrm{Fe}{ }^{\mathrm{III}} \mathrm{OOH}\right.$, Bayferrox 943), hematite $\left(\mathrm{Fe}^{\mathrm{III}}{ }_{2} \mathrm{O}_{3}\right.$, Bayferrox $\left.105 \mathrm{M}\right)$, and goethite $\left(\alpha-\mathrm{Fe}{ }^{\mathrm{III}} \mathrm{OOH}\right.$, Bayferrox 3920$)$ were purchased from LANXESS Corp. All IBSMs were screened with sieves and mineral particles under $150 \mu \mathrm{m}$ were collected for use. The IBSMs were identified by X-ray diffraction (XRD) to investigate their purity and identity. All IBSMs showed a good agreement with those in Joint Committee on Powder Diffraction Standards (JCPDS) diffraction data files (JADE 9, Materials Data, Inc.) (data not shown).

\subsection{Bacteria culturing}

Aerobically cultured CN32 cells in tryptic soy broth (TSB, $30 \mathrm{~g} / \mathrm{L}$ ) were prepared at $26^{\circ} \mathrm{C}$ under continuous shaking at $150 \mathrm{rpm}$. They were harvested at late growth phase and washed twice in $30 \mathrm{mM}$ PIPES buffer ( $\mathrm{pH} \mathrm{7)}$ to remove residual TSB by centrifuging at $12000 \mathrm{rpm}$ for $5 \mathrm{~min}$. Modified defined medium (MDM) was prepared using $30 \mathrm{mM}$ PIPES buffer without $\mathrm{NaHCO}_{3}$ to avoid the formation of siderite ( $\left.\mathrm{Fe}(\mathrm{II}) \mathrm{CO}_{3}\right)(\mathrm{Bae}$ and Lee 2012) and its $\mathrm{pH}$ was adjusted to 7.0 by adding $2 \mathrm{M} \mathrm{NaOH}$. The prepared $\mathrm{MDM}$ was autoclaved, cooled at ambient temperature $\left(25 \pm 0.5^{\circ} \mathrm{C}\right)$.

\subsection{Removal of IBSM reactivities and reductive degradations of TNT and RDX}

Batch experiments for reductive degradation of TNT and RDX were conducted under anoxic condition using $250 \mathrm{~mL}$ of serum bottles sealed with aluminum cap and butyl rubber stopper. At first, we investigated abiotic degradation of TNT and RDX in magnetite, green rust, lepidocrocite, goethite, and hematite suspensions to remove their potentials for reductive degradation of TNT and RDX. MDM $(200 \mathrm{~mL})$ was transferred to the bottles containing $0.01 \mathrm{~g}$ of five different IBSMs (magnetite, green rust, lepidocrocite, goethite, and hematite). TNT $(37.4 \mathrm{mM})$ and RDX $(81 \mathrm{mM})$ stock solutions in methanol were prepared and its aliquot amount were (TNT $1.176 \mathrm{~mL}$, RDX $110 \mu \mathrm{L})$ spiked to each bottle by a gastight syringe at the same time. The initial concentrations of TNT and RDX were 0.22 and $0.05 \mathrm{mM}$, respectively. The bottles were rapidly taken out of the anaerobic chamber and mounted on a tumbler at $7.5 \mathrm{rpm}$. After confirming that each IBSM could not degrade TNT and RDX, we centrifuged each bottle, washed once by DDW, and recollected the IBSMs by vacuum pump and $0.2 \mu \mathrm{m}$ sterilized PTFE membrane filter (Whatman). The similar procedure was used for sample preparation of the batch experiments to investigate the reductive degradation of TNT and RDX by bio-reduced IBSMs using CN32. MDM $(180 \mathrm{~mL})$ was transferred to the bottles containing $0.01 \mathrm{~g}$ of five different IBSMs (magnetite, green rust, lepidocrocite, goethite, hematite) and $5 \mathrm{~mL}$ of sodium lactate $(30 \mathrm{mM}$, electron donor) and AQS (100 $\mu \mathrm{M}$, electron transfer mediator) were added by a syringe with $0.2 \mu \mathrm{m}$ sterilized PTFE membrane filter. Washed cells $(10 \mathrm{~mL})$ were transferred to the bottles $\left(3.33 \times 10^{7}\right.$ cells $\left./ \mathrm{mL}\right)$. Initial concentrations of TNT $(0.22 \mathrm{mM})$ and RDX $(0.05 \mathrm{mM})$ were injected into each bottle. The bottles were rapidly taken out of the anaerobic chamber and mounted on a shaking incubator at $150 \mathrm{rpm}$ at $26^{\circ} \mathrm{C}$. The reductive degradation kinetics of TNT and RDX were investigated by its aqueous concentration at each sampling time. Control $(\mathrm{CN} 32+\mathrm{MDM})$ was prepared to evaluate the loss of target compounds due to 
microbial degradation of TNT and RDX.

\subsection{Analytical procedures}

TNT, RDX, and their transformation products such as 4-amino-dinitrotoluene (4-ADNT), Hexahydro-1-nitroso-3,5-dinitro-1,3,5-triazine (MNX), Hexahydro-1,3-dinitroso-5-nitro-1,3,5-triazine (DNX), and Hexahydro-1,3,5-trinitroso-1,3,5-triazine (TNX) were analyzed using high-performance liquid chromatography (HPLC, Varian) with a variable wavelength photodiode array (PDA, 335 Varian) detector at $230 \mathrm{~nm}$. The filtered samples were automatically injected into a RP C18 column (Shiseido, $250 \mathrm{~mm} \times 4.6 \mathrm{~mm}$ ) at ambient temperature. A mobile phase consisting of $40 \%$ phosphate buffer (pH 7.0) and 60\% methanol was used at a flow rate of $1.2 \mathrm{~mL} / \mathrm{min}$ (Bae 2006). TNT, RDX, and 4-ADNT were compared to certificated analytical standards in acetonitrile at known concentrations. Total iron was quantified by the Ferrozine assay (Stookey 1970). Each $1.5 \mathrm{~mL}$ aliquot sample from incubation bottles was diluted in $4.5 \mathrm{~mL}$ of $4 \mathrm{~N} \mathrm{HCl}$ and $0.9 \mathrm{~mL}$ aliquot of the diluted solution was added to Ferrozine solution, and then quantified at $562 \mathrm{~nm}$ wavelength of UV/vis spectrophotometer (Agilent 8453).

XRD analysis was conducted for the identification of initial and secondary mineral phases using Rigaku automated diffractometer with $\mathrm{Cu} \mathrm{KN}$ (D/MAX-2500). The bottles were centrifuged at $3000 \mathrm{rpm}$ for $5 \mathrm{~min}$ at last sampling time. The precipitates were collected by filteration and dried in anaerobic chamber for $24 \mathrm{~h}$. The samples were scanned between $5^{\circ}$ to $80^{\circ} 2 \theta$ with scan speed of $4^{\circ}$ $\mathrm{min}^{-1}$. The XRD patterns of secondary minerals were analyzed with JCPDS diffraction data files.

The structure and morphology of IBSM particles were examined by TEM (Tecnai F20 model, Philips). Bottles were centrifuged at $3000 \mathrm{rpm}$ for $5 \mathrm{~min}$. Suspensions containing particles of IBSMs were replaced by ethanol in the anaerobic chamber and then dispersed by sonication for $4 \mathrm{~min}$. A droplet of suspension was put on 300-mesh Cu TEM grids with a carbon film and dried in the anaerobic condition for $2 \mathrm{~h}$.

\section{Result and discussion}

\subsection{Abiotic degradation of TNT and RDX by IBSMs}

Fig. 1 shows the reactivity removal of abiotic reduction potential of 5 IBSMs (green rust, magnetite, lepidocrocite, hematite and goethite) that can be used for TNT and RDX degradation. Green rust degraded $86.3 \%$ of TNT in first $1 \mathrm{~h}$ and approximately $100 \%$ of TNT in $44 \mathrm{~h}$ (Fig. 1(a)). To our knowledge, the degradation of TNT by green rust is firstly introduced by this study. Green rust also degraded $64.6 \%$ of RDX in $1 \mathrm{~h}$ and approximately $93 \%$ of RDX in $20 \mathrm{~h}$ exhibiting the highest reactivity to degrade contaminants among studied IBSMs (Fig. 1(b)). It has been reported that sulfate green rust $(6 \mathrm{~g} / \mathrm{L})$ degraded $100 \%$ of $\mathrm{RDX}(40 \mu \mathrm{M})$ in the presence of $\mathrm{K}_{2} \mathrm{SO}_{4}(50 \mathrm{mM})$ at $\mathrm{pH}$ 7 in $1 \mathrm{~h}$ (Larese-Casanovva and Scherer 2008). Our experimental results showed relatively slower kinetics compared to the previous research because 1.25 times higher concentrations of RDX and 12 times lower amount of green rust were used in our research than those of the previous research. The same amount of TNT and RDX were re-added after 44 and $20 \mathrm{~h}$, respectively, to investigate the remaining reactivity of green rust. Fig. 1 shows that TNT and RDX were not further degraded by green rust after $60 \mathrm{~h}$. This was due to the oxidation of Fe(II) on the surface of the green rust to 


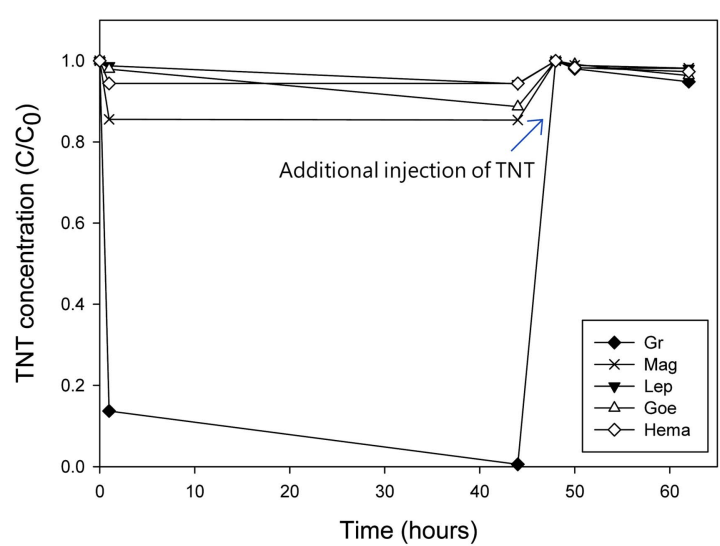

(a)

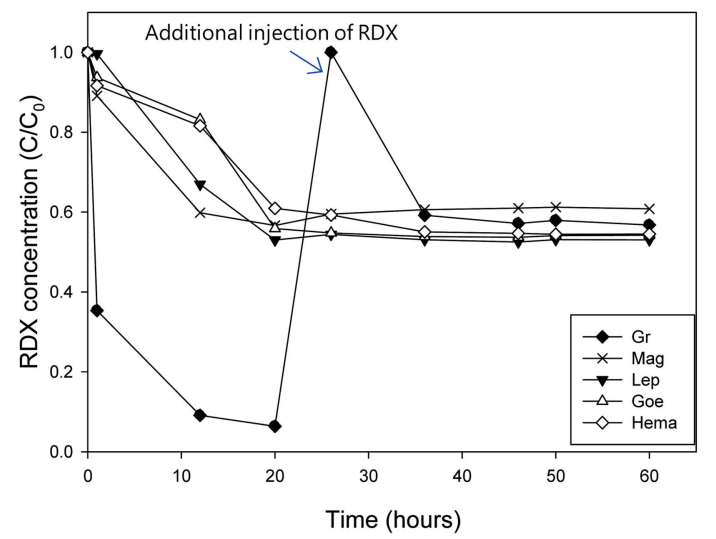

(b)

Fig. 1 Abiotic reductive degradations of (a) TNT and (b) RDX by IBSMs (green rust, magnetite, lepidocrocite, goethite, and hematite) $(0.1 \mathrm{~g} / 200 \mathrm{~mL})$ in DDW. The initial concentrations of TNT and RDX were 0.22 and $0.05 \mathrm{mM}$, respectively

Fe(III) resulting in formation of magnetite by degrading TNT and RDX. XRD and TEM analysis in section 3.2 can explain the oxidation of green rust to magnetite. Magnetite degraded $17 \%$ of TNT in $44 \mathrm{~h}$. It was relatively lower than green rust because magnetite composed of $1: 2$ ratio of $\mathrm{Fe}(\mathrm{II})$ : $\mathrm{Fe}$ (III) ions (Lee and Batchelor 2002a). However, TNT was not degraded by magnetite after readdition of TNT. The rest of other three IBSMs (lepidocrocite, hematite and goethite) did not show significant degradation of TNT. This was because they are Fe(II) deficient IBSMs that could not deliver electrons to TNT. Approximately $40 \%$ of RDX was removed in $58 \mathrm{~h}$ by magnetite, lepidocrocite, goethite and hematite (Fig. 1(b)), but expected by-products such as MNX, DNX and TNX were not detected during the reaction indicating that adsorption of RDX on the surface of IBSMs might be occurred.

\subsection{Enhanced degradation of TNT by interaction of reactivity removed IBSMs and CN32}

Fig. 2 shows the kinetics of TNT degradation by the interaction between reactivity removed IBSMs and CN32. The reactivity removed IBSMs regained their reactivity to degrade TNT by adding CN32. Especially, bio-reduced magnetite by CN32 showed the degradation of TNT $(20.2 \%)$ in $58 \mathrm{~h}$ and the highest kinetic constant $\left(0.0039 \mathrm{~h}^{-1}\right)$, followed green rust $\left(0.0022 \mathrm{~h}^{-1}\right)$, goethite $\left(0.0017 \mathrm{~h}^{-1}\right)$, lepidocrocite $\left(0.0016 \mathrm{~h}^{-1}\right)$ and hematite $\left(0.0006 \mathrm{~h}^{-1}\right)$ (Table 1). The control containing only CN32 and MDM showed low degradation of TNT (8.5\%) and kinetic constant $\left(0.0012 \mathrm{~h}^{-1}\right)$ in $58 \mathrm{~h}$. This indicates that the degradation kinetic of TNT by each interaction was significantly different depending on types of IBSM.

$3 \mathrm{~N} \mathrm{HCl}$ extractable $\mathrm{Fe}(\mathrm{II})$ concentrations of bio-reduced IBSMs were measured to investigate the effect of $\mathrm{Fe}$ (II) production on the degradation of TNT (Fig. 3). 3N HCl extractable $\mathrm{Fe}$ (II) in the IBSM suspensions with CN32 during the reductive degradation of TNT increased in $58 \mathrm{~h}$. Magnetite and green rust, which showed high kinetic constants $\left(0.0039\right.$ and $0.0022 \mathrm{~h}^{-1}$, respectively), exhibited high Fe(II) productions (0.068 and $0.073 \mathrm{mM}$, respectively) among studied 


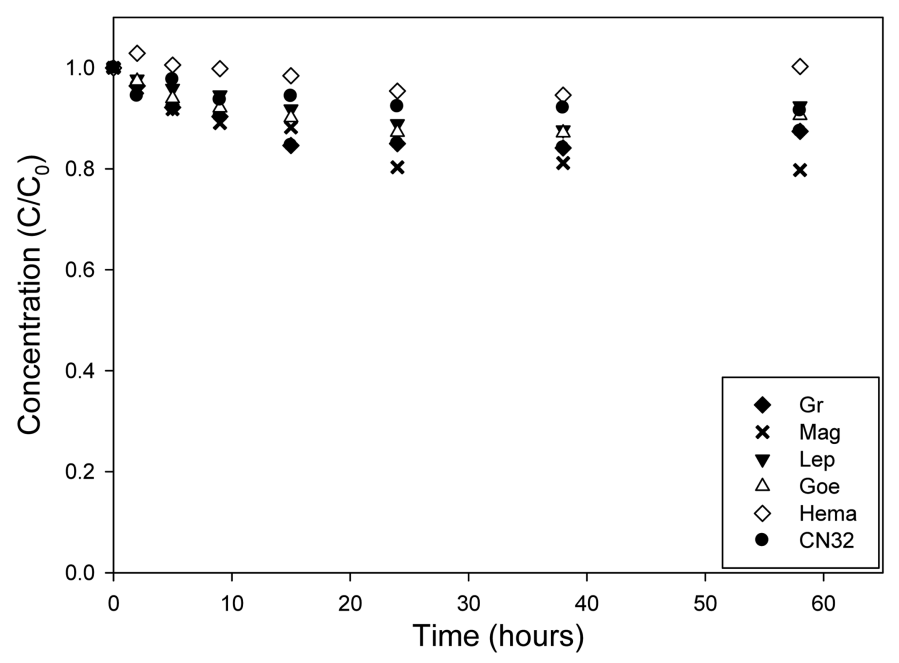

Fig. 2 Enhanced reductive degradation of TNT by bio-reduced IBSMs (green rust, magnetite, lepidocrocite, goethite, and hematite) with $\mathrm{CN} 32$ and only $\mathrm{CN} 32$ in MDM at pH 7 (PIPES). The initial concentration of TNT was $0.22 \mathrm{mM}$

Table 1 Observed kinetic rate constants for the reductive degradations of TNT and RDX by bio-reduced IBSMs. The data for CN32, green rust, magnetite, lepidocrocite, hematite and goethite were cited from Fig. 2 and Fig. 7

\begin{tabular}{ccccccc}
\hline \hline & CN32 & Green rust & Magnetite & Lepidocrocite & Goethite & Hematite \\
\hline TNT $\left(h^{-1}\right)$ & 0.0012 & 0.0022 & 0.0039 & 0.0016 & 0.0017 & 0.0006 \\
RDX $\left(h^{-1}\right)$ & 0.0432 & 0.0757 & 0.1700 & 0.1811 & 0.0394 & 0.0495 \\
\hline
\end{tabular}

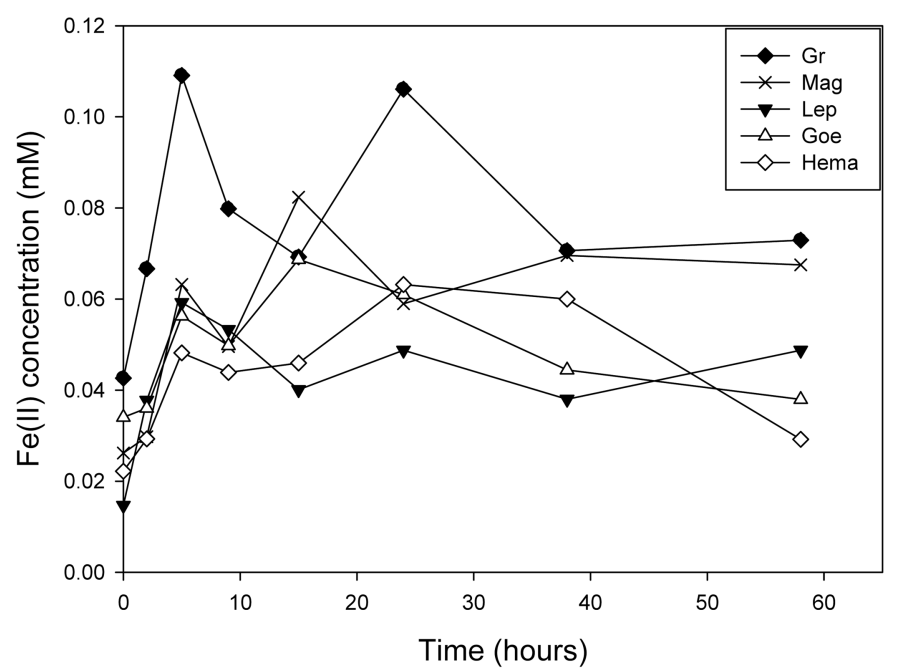

Fig. 3 Production of $3 \mathrm{~N} \mathrm{HCl}$ extractable $\mathrm{Fe}(\mathrm{II})$ during the reductive degradation of TNT by interaction of bioreduced IBSMs (green rust, magnetite, lepidocrocite, goethite, hematite) $(0.1 \mathrm{~g} / 200 \mathrm{~mL})$ and $\mathrm{CN} 32$ in MDM at $\mathrm{pH} 7$ (PIPES) 
IBSMs. Magnetite and green rust containing Fe(II) in their structures are more easily reduced by CN32 than Fe(II) deficient IBSMs (Bae and Lee 2012). Lepidocrocite, goethite, and hematite showed that relatively lower amount of $\mathrm{Fe}(\mathrm{II})(0.02-0.043 \mathrm{mM})$ was reduced by $\mathrm{CN} 32$. The bioreduction of well crystallized minerals (i.e., hematite and goethite) has been reported to be more difficult than that of poorly-crystallized minerals (Maithreepala and Doong 2009, Roden 2003). Therefore, the results obtained by this study showed that TNT degradation was significantly affected by bio-reduction of $\mathrm{Fe}$ (III) to $\mathrm{Fe}(\mathrm{II})$ by $\mathrm{CN} 32$.

XRD and TEM analysis were conducted to investigate mineral transformation during the reductive degradation of TNT by reactivity removed IBSMs and CN32. Fig. 4 shows the XRD patterns of green rust, magnetite and lepidocrocite which exhibited high reactivity to degrade TNT compared to that of goethite and hematite. The peaks of green rust had changed to peaks of magnetite (Fig. 4(a)). This was due to the oxidation of $\mathrm{Fe}$ (II) to $\mathrm{Fe}$ (III) for reductive degradation of TNT, resulting in the change of the green rust to magnetite (Lee and Batchelor 2002b). Figs. 4(b) and 4(c) show the XRD

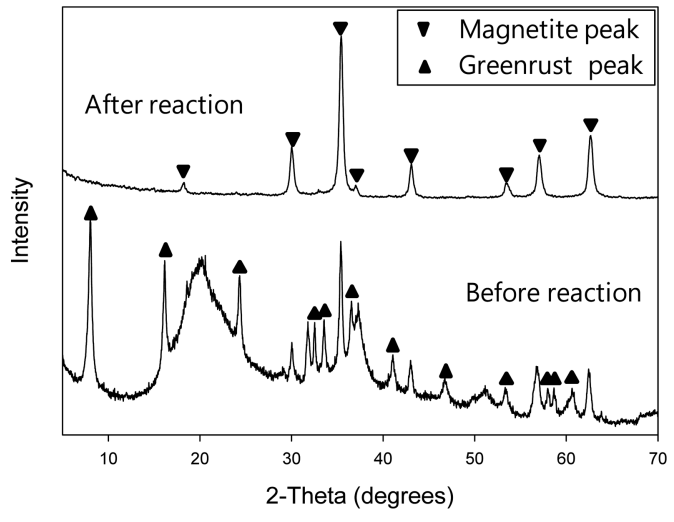

(a)

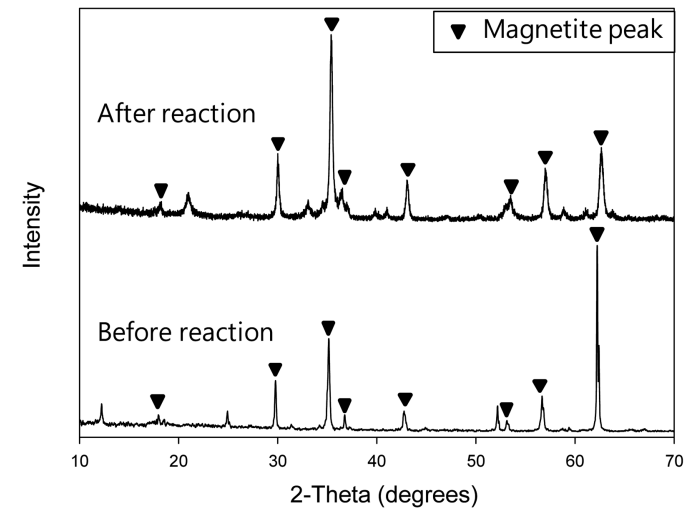

(b)

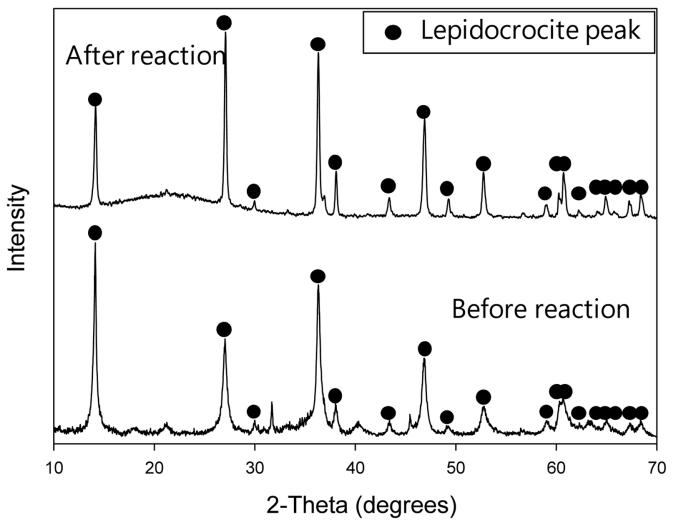

(c)

Fig. 4 (a) XRD pattern showing the transformation of green rust to magnetite during the reductive degradation of TNT by bio-reduced green rust, (b) and (c) XRD patterns showing no mineral transformations of magnetite and lepidocrocite during the enhanced reductive degradation of TNT: peaks of green rust ( $\boldsymbol{\Delta}$ ), magnetite ( $\boldsymbol{\nabla}$ ), and lepidocrocite ( 
patterns of magnetite and lepidocrocite did not significantly change during the reaction. Bae and Lee reported biotransformation of lepidocrocite and magnetite to biogenic vivianite in the presence of CN32 and phosphate in $32 \mathrm{~d}$ (2012). However, mineral transformation of magnetite and lepidocrocite was not observed in this study due to the absence of phosphate and the not enough time for mineral transformation of IBSMs $(58 \mathrm{~h})$ in this study. Fig. 5 shows the TEM images of green rust, magnetite, and lepidocrocite before and after degradation of TNT. Hexagonal shaped green rust (Fig. 5(a)) (Legrand et al. 2001) was transformed to spherical plate shape of magnetite (Fig. 5(b)). This also indicates that transformation of green rust to magnetite through degradation of TNT as similarly observed in XRD. A spherical shape of chemogenic magnetite (control) composed of non-uniform particles (30-100 nm) (Bae and Lee 2010) (Fig. 5(c)) and nano-sized chemogenic lepidocrocite (50$200 \mathrm{~nm}$ ) with quadrangular and rectangular shapes (Fig. 5(d)) were not changed after the reductive degradation of TNT in this study. The results of TEM analysis are consistent with XRD analysis. The results of Fe productions, XRD, and TEM concluded that Fe(II) production during the interaction of green rust, magnetite, and lepidocrocite with $\mathrm{CN} 32$ was the key factor to enhance the reductive degradation of TNT in this study not by formation of reactive secondary minerals such as green rust and vivianite.
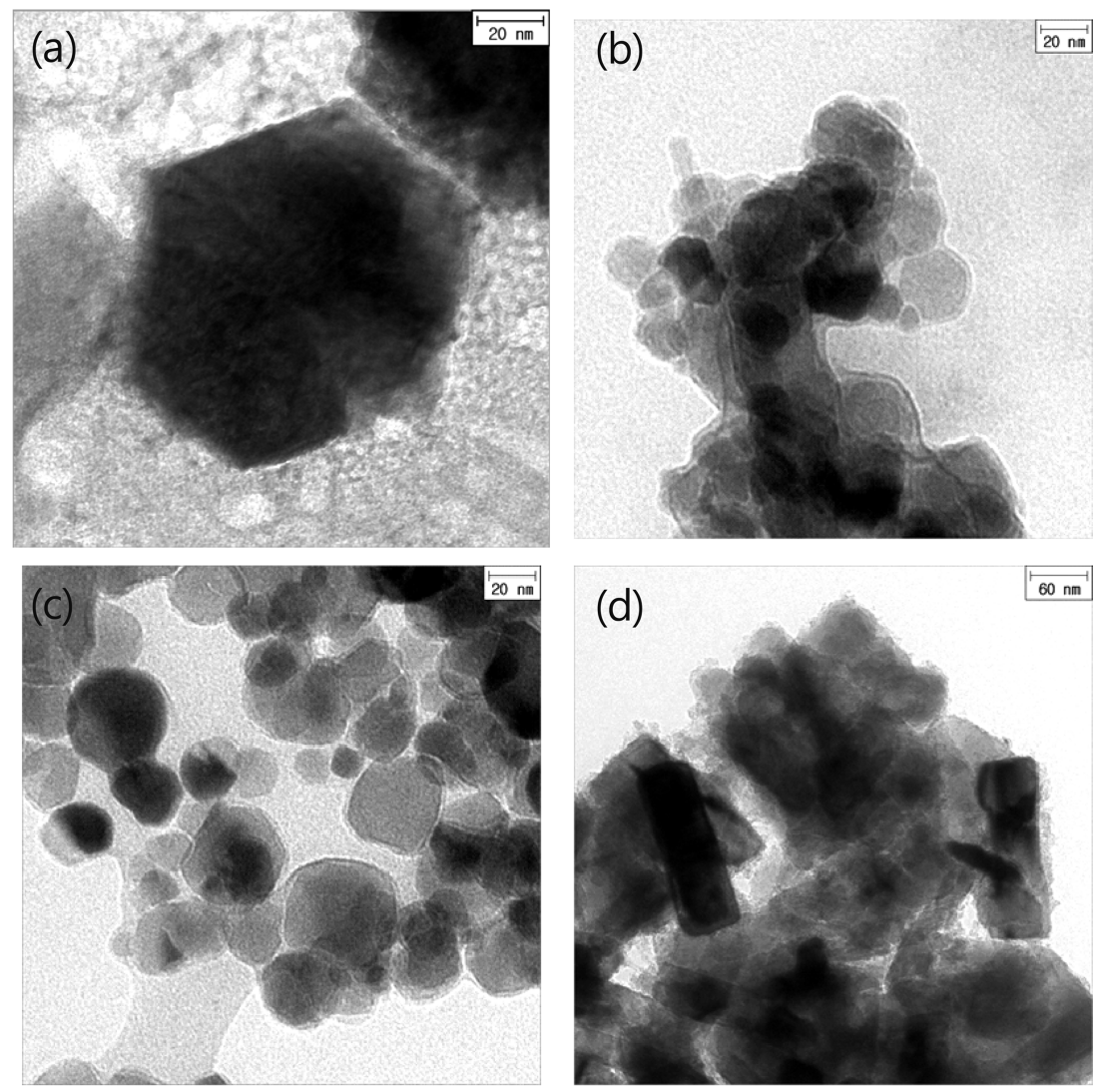

Fig. 5 TEM images of (a) green rust and (b) magnetite before and after the reductive degradation of TNT at $58 \mathrm{~h}$, TEM image of (c) chemogenic magnetite and (d) chemogenic lepidocrocite after the reductive degradation of TNT showing no mineral transformations 


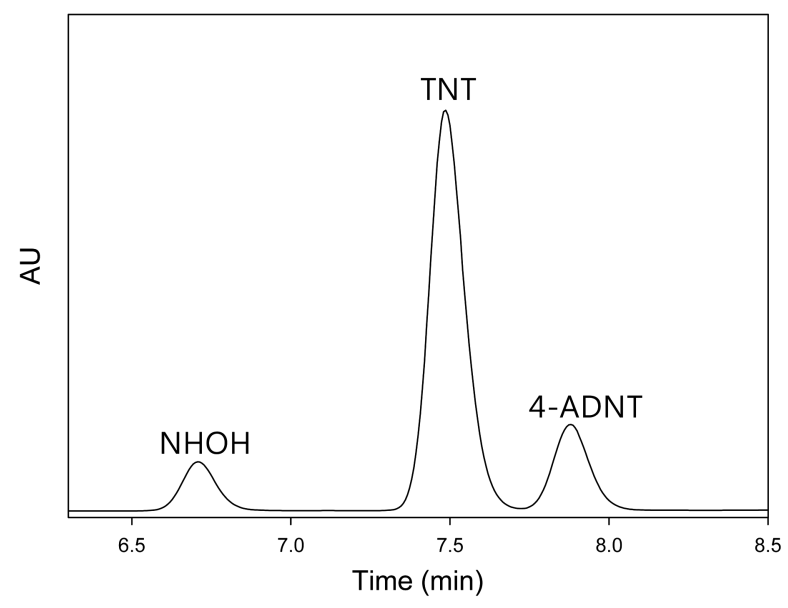

Fig. 6 HPLC chromatogram showing the production of 4-ADNT during the enhanced reductive degradation of TNT by bio-reduced green rust at $38 \mathrm{~h}$

Byproduct study was carried out to investigate reaction mechanism of degradation of TNT. Fig. 6 shows the peak of 4-ADNT in TNT degradation by the interaction of the reactivity removed green rust and CN32. Borch et al. reported that TNT was degraded by ferrihydrite in the presence of AQDS to 2-amino-dinitrotoluene (2-ADNT), 4-ADNT, 2,6-diamino-4-nitrotoluene (2,6-DANT), 2,4diamino-6-nitrotoluene (2,4-DANT) (2005). However, 4-ADNT increased as TNT decreased in our results suggesting that no transformation pathway to 2,4-DANT. It has been reported that degradation of TNT to 4-ADNT was much favorable compared to the 2-ADNT pathway which is consistent to the results obtained by this study (Kaplan and Kaplan 1982). Formation of 4-ADNT has been also observed in other IBSMs with CN32 in this study. Other IBSMs (magnetite and lepidocrocite) also showed the increase of 4-ADNT concentration as similar to the result of green rust indicating that the degradation pathway of TNT was same as green rust. The proposed transformation pathway of TNT by the interaction of the reactivity removed IBSMs and CN32 is followed below:

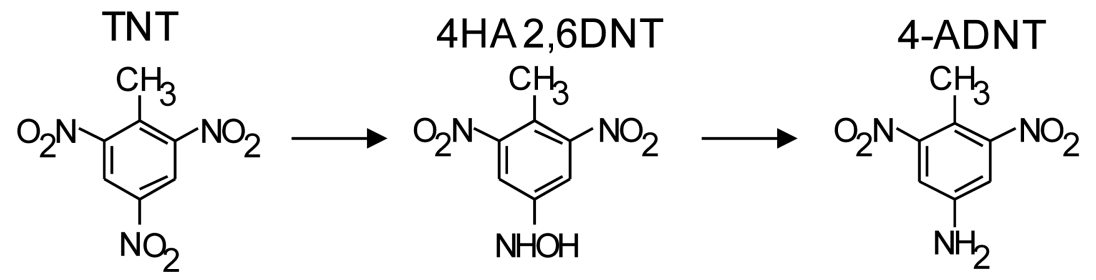

\subsection{Enhanced degradation of RDX by interaction of reactivity removed IBSMs and CN32}

Fig. 7 shows the kinetics of RDX degradation by the interaction between reactivity removed IBSMs and CN32. RDX degradation by reactivity removed IBSMs was enhanced by the addition of 


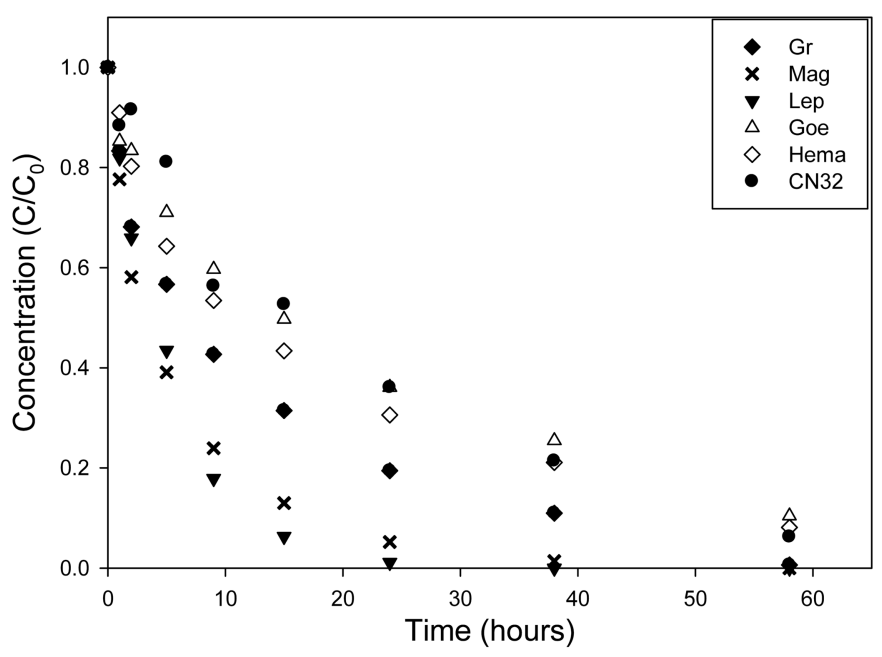

Fig. 7 Enhanced reductive degradation of RDX by bio-reduced IBSMs (green rust, magnetite, lepidocrocite, goethite, and hematite) with $\mathrm{CN} 32$ and only $\mathrm{CN} 32$ in MDM at $\mathrm{pH} 7$ (PIPES). The initial concentration of RDX was $0.05 \mathrm{mM}$

CN32. Green rust, magnetite, and lepidocrocite degraded $100 \%$ of RDX in $58 \mathrm{~h}$, and goethite and hematite showed more than $90 \%$ of RDX degradation. The highest rate constant was obtained by interaction of lepidocrocite and CN32 $\left(0.1811 \mathrm{~h}^{-1}\right)$ during RDX degradation, followed by magnetite $\left(0.1700 \mathrm{~h}^{-1}\right)$, green rust $\left(0.0757 \mathrm{~h}^{-1}\right)$, hematite $\left(0.0495 \mathrm{~h}^{-1}\right)$, and goethite $\left(0.0394 \mathrm{~h}^{-1}\right)$. However, the control (CN32 + MDM) also showed biotic degradation of RDX (90\%) in $58 \mathrm{~d}$ induced by CN32. Kwon and Finneran has also reported biotic degradation of RDX by DIRBs such as Geobacteraceae metallireducens strain GS-15, Anaeromyxobacter dehalogenans strain K, Desulfitobacterium chlororespirans strain Co23, and Shewanella oneidensis Strain MR1 (2008). The addition of CN32 to green rust, magnetite, and lepidocrocite exhibited 1.75, 3.93 and 4.19 times higher RDX degradation kinetic constants than that of biotic degradation by CN32 (Table 1). This indicates that degradation of RDX was significantly enhanced by adding CN32 in green rust, magnetite, and lepidocrocite suspensions. Kwon and Finneran also reported enhanced RDX and HMX degradation by the interaction between poorly crystalline $\mathrm{Fe}(\mathrm{III})$ oxide and several DIRBs in the presence of lactate and AQDS (2008). However, the experimental data in this research firstly showed the enhanced RDX degradation by reactivity removed IBSMs and CN32.

$3 \mathrm{~N} \mathrm{HCl}$ extractable $\mathrm{Fe}(\mathrm{II})$ concentrations of bio-reduced IBSMs were measured to investigate the effect of $\mathrm{Fe}$ (II) production on the reduction of RDX (Fig. 8). 3N HCl extractable Fe(II) in the IBSM suspensions with CN32 during the reductive degradation of RDX were significantly increased in 58 $\mathrm{h}$. Lepidocrocite and magnetite, which showed the fast kinetics of RDX degradation, resulted in high $\mathrm{Fe}(\mathrm{II})$ production $(0.71$ and $0.57 \mathrm{mM}$, respectively) in $58 \mathrm{~h}$, while approximately $0.2 \mathrm{mM}$ of $\mathrm{Fe}(\mathrm{II})$ was produced from green rust, goethite, and hematite. As mentioned above in the discussion of TNT degradation, the amount of bio-reduced Fe(II) by the interaction of CN32 and IBSMs was the key factor for degradation of RDX. XRD and TEM analysis were conducted to investigate mineral transformation of IBSMs by CN32 in degradation of RDX. XRD and TEM analysis (data not shown) revealed that green rust was transformed to magnetite and no significant changes were 


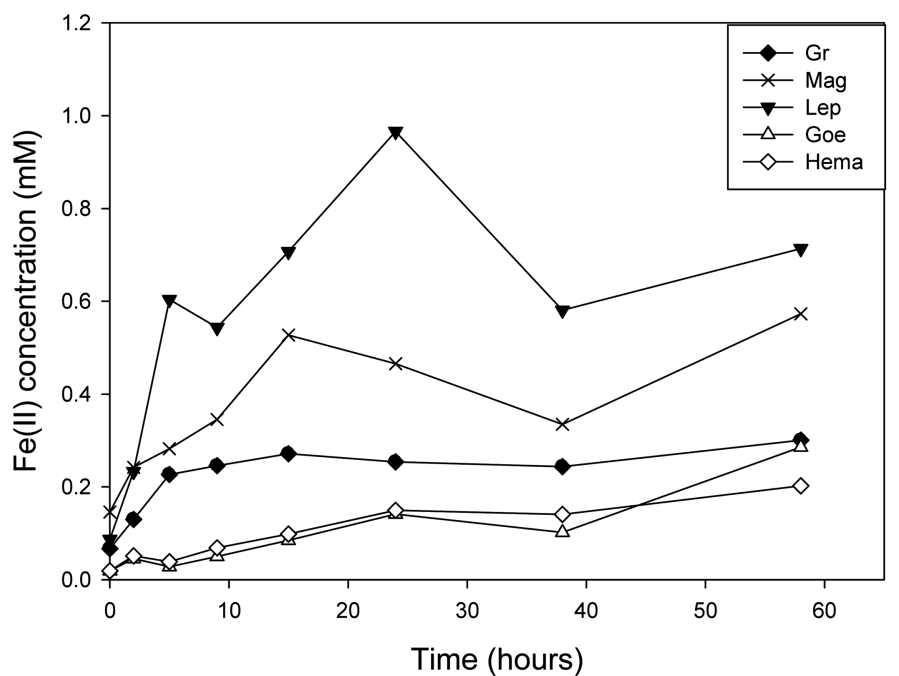

Fig. 8 Production of $3 \mathrm{~N} \mathrm{HCl}$ extractable Fe(II) during the reductive degradation of RDX by interaction of bioreduced IBSMs (green rust, magnetite, lepidocrocite, goethite, hematite) $(0.1 \mathrm{~g} / 200 \mathrm{~mL})$ and CN32 in MDM at $\mathrm{pH} 7$ (PIPES)

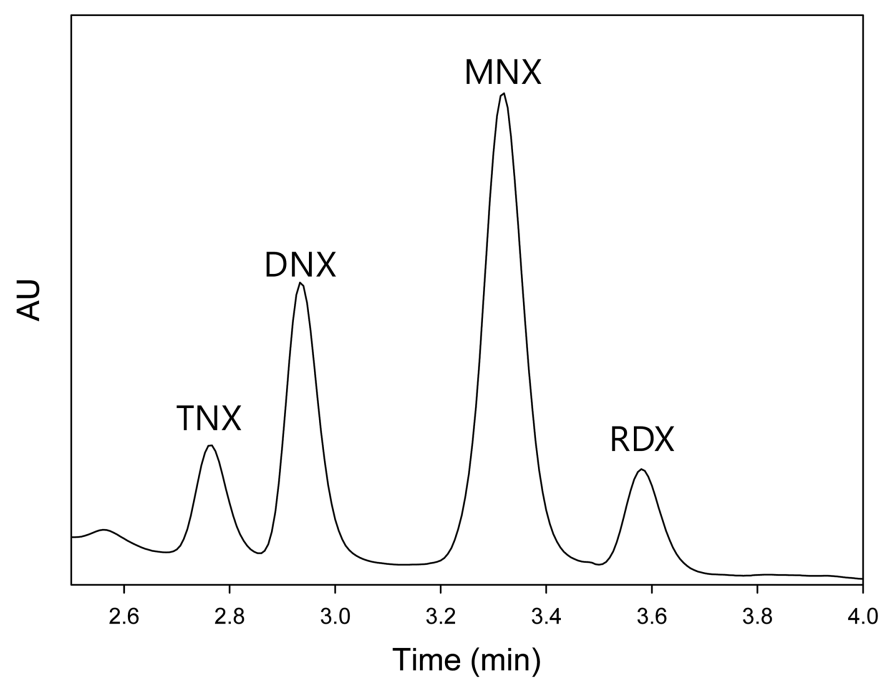

Fig. 9 HPLC chromatogram showing the production of MNX, DNX, and TNX during the enhanced reductive degradation of RDX by bio-reduced green rust at $38 \mathrm{~h}$

observed in magnetite and lepidocrocite. This indicated that the enhanced degradation of RDX by addition of CN32 in IBSM suspensions was occurred by $\mathrm{Fe}(\mathrm{II})$ production not by mineral transformation which is consistent with the result obtained from TNT experiment.

Byproduct study was carried out to investigate reaction mechanism of degradation of RDX. Fig. 9 shows the peak of MNX, DNX, and TNX during the RDX degradation by the interaction of 
reactivity removed green rust and $\mathrm{CN} 32$. This indicates that RDX was reduced to MNX, DNX, and TNX as a subsequent reduction of three nitro-on RDX to nitroso- (Kwon and Finneran 2006). It has been also reported that RDX was reduced to MNX, DNX, and TNX by magnetite and zero valent iron (Gregory et al. 2004, Naja et al. 2008). Other IBSMs (magnetite and lepidocrocite) also showed the increases of MNX, DNX, and TNX concentrations as similar to the result of green rust indicating that the degradation pathway of RDX was same as green rust case. The proposed transformation pathway of RDX by the interaction of the reactivity removed IBSMs and CN32 is followed below:<smiles>[X][M]O[N+]([O-])(O)C1CN([N+](=O)[O-])CN([N+](=O)[O-])C1</smiles>

\section{Conclusions}

We have observed the enhanced degradation of TNT and RDX by adding CN32 to reactivity removed IBSMs. The change in total $\mathrm{Fe}(\mathrm{II})$ revealed that $\mathrm{Fe}(\mathrm{II})$ produced from the interaction of CN32 and IBSMs was the key factor to enhanced degradation of TNT and RDX. To identify mineral transformation XRD and TEM analysis were conducted during the bio-reduced IBSMs. However, only green rust was transformed to magnetite after reductive degradation of TNT and RDX and no transformation was observed by other IBSMs. TNT was reductively transformed to 4ADNT by produced $\mathrm{Fe}(\mathrm{II})$, while RDX was reduced to MNX, DNX, and TNX. It was proved that $\mathrm{Fe}$ (II) can be constantly produced from the interaction of the reactivity removed IBSMs and DIRB and this produced $\mathrm{Fe}(\mathrm{II})$ can establish a redox cycle to reductively transform explosives. The result obtained from this study can provide a fundamental knowledge to develop reducing environments of IBSMs for removal of explosives by the interaction of DIRB and IBSMs when reactivity of IBSMs decreased.

\section{References}

Adrian, N.R., Arnett, C.M. and Hickey, R.F. (2003), "Stimulating the anaerobic biodegradation of explosives by the addition of hydrogen or electron donors that produce hydrogen", Water Res., 37(14), 3499-3507.

Adrian, N.R. and Arnett, C.M. (2004), "Anaerobic biodegradation of hexahydro-1,3,5-trinitro-1,3,5-triazine (RDX) by Acetobacterium malicum strain HAAP-1 isolated from a methanogenic mixed culture", Curr. Microbiol., 48(5), 332-340.

Boopathy, R. and Kulpa, C.F. (1992), "Trinitrotoluene (TNT) as a sole nitrogen source for a sulfate-reducing bacterium Desulfovibrio sp. (B Strain) usolated from an anaerobic digester", Curr. Microbiol., 25(4), 235-241.

Boopathy, R. and Manning, J.F. (2000), "Laboratory treatability study on hexahydro-1,3,5-trinitro-1,3,5-triazine(RDX-) contaminated soil from the Iowa army ammunition plant", Water Environ. Res., 72(2), 238-242.

Borch, T., Inskeep, W.P., Harwood, J.A. and Gerlach, R. (2005), "Impact of ferrihydrite and anthraquinone-2,6disulfonate on the reductive transformation of 2,4,6-trinitrotoluene by a gram positive fermenting bacterium", 
Environ. Sci. Technol., 39(18), 7126-7133.

Bae, B. (2006), "Reduction of high explosives (HMX, RDX, and TNT) using micro- and nano- size zero valent iron : Comparison of kinetic constants and intermediates behavior", J. KoSSGE, 11(6), 83-91.

Bae, S. and Lee, W. (2010), "Inhibition of nZVI reactivity by magnetite during the reductive degradation of 1,1,1-TCA in nZVI/magnetite suspension", Appl. Catal. B: Environ., 96(1-2), 10-17.

Bae, S. and Lee, W. (2012), "Enhanced reductive degradation of carbon tetrachloride by biogenic vivianite and Fe(II)", Geochim. Cosmochim. Ac., doi: 10.1016/j.gca.2012.02.023

Fredrickson, J.K., Zachara, J.M., Kennedy, D.W., Dong, H., Onstott, T.C., Jinman, N.W. and Li, S. (1998), "Biogenic iron mineralization accompanying the dissimilatory reduction of hydrous ferric oxide by a groundwater bacterium", Geochim. Cosmochim. Ac., 62(19-20), 3239-3257.

Gregory, K.B., Larese-Casanova, P., Parkin, G.F. and Scherer, M.M. (2004), "Abiotic transformation of hexahydro-1,3,5-trinitro-1,3,5-triazine by Fe(II) bound to magnetite", Environ. Sci. Technol., 38(5), 1408-1414.

Hundal, L.S., Shea, P.J., Comfort, S.D., Powers, W.L. and Singh, J. (1997a), "Long-term TNT sorption and boundresidue formation in soil", J. Environ. Qual., 26(3), 894-904.

Hundal, L.S., Singh, J., Bier, E.L., Shea, P.J., Comport, S.D. and Powers, W.L. (1997b), "Removal of TNT and RDX from water and soil using iron metal", Environ. Pollut., 97(1-2), 55-64.

Huang, S., Lindahl, P.A., Wang, C., Bennett, G.N., Rudolph, F.B. and Hughes, J.B. (2000), "2,4,6-Trinitrotoluene reduction by carbon monoxide dehydrogenase from Clostridium thermoaceticum", Appl. Environ. Microb., 66(4), 1474-1478.

Kaplan, D.L. and Kaplan, A.M. (1982), “2,4,6-trinitrotoluene-surfactant complexes: Decomposition, mutagenicity, and soil leaching studies", Environ. Sci. Technol., 16(9), 566-571.

Kwon, M.J. and Finneran, K.T. (2006), "Microbially mediated biodegradation of hexahydro-1,3,5-trinitro-1,3,5triazine by extracelluar electron shuttling compounds", Appl. Environ. Microb., 72(9), 5933-5941.

Kwon, M.J. and Finneran, K.T. (2008), "Hexahydro-1,3,5-trinitro-1,3,5-triazine (RDX) and octahydro-1,3,5,7tetranitro-1,3,5,7-tetrazocine (HMX) biodegradation kinetics amongst several Fe(III)-reducing genera", Soil Sediment Contam. 17(2), 189-203.

Legrand, L., Abdelmoula, M., Gehin, A., Chausse, A. and Genin, J.M.R. (2001), "Electrochemical formation of a new $\mathrm{Fe}(\mathrm{II})-\mathrm{Fe}(\mathrm{III})$ hydroxy-carbonate green rust: characterisation and morphology", Electrochim. Acta, 46(12), 1815-1822.

Lee, W. and Batchelor, B. (2002a), "Reductive dechlorination of chlorinated ethylenes by iron-bearing soil minerals. 1. Pyrite and magnetite", Environ. Sci. Technol., 36(23), 5147-5154.

Lee, W. and Batchelor, B. (2002b), "Reductive dechlorination of chlorinated ethylenes by iron-bearing soil minerals. 2. Green rust", Environ. Sci. Technol., 36(24), 5348-5354.

Larese-Casanova, P. and Scherer, M.M. (2008), “Abiotic transformation of hexahydro-1,3,5-trinitro-1,3,5-triazine (RDX) by green rusts", Environ. Sci. Technol., 42(11), 3975-3981.

Lotufo, G., Sunahara, G.I., Hawari, J. and Kuperman, R.G. (2009), Ecotoxicology of Explosives, CRC Press, Boca Raton, FL.

Meyers, S.K., Deng, S., Basta, N.T., Clarkson, W.W. and Wilber, G.G. (2007), "Long-term explosive contamination in soil: Effects on soil microbial community and bioremediation", Soil Sediment Contam., 16(1), 61-77.

Maithreepala, R.A. and Doong, R.A. (2009), "Transformation of carbon tetrachloride by biogenic iron species in the presence of Geobacter sulfurreducens and electron shuttles", J. Hazard. Mater., 164(1), 337-344.

Naja, J., Halasz, A., Thiboutot, S., Ampleman, G and Hawai, J. (2008), "Degradation of Hexahydro-1,3,5trinitro-1,3,5-triazine (RDX) using zerovalent iron nanoparticles", Environ. Sci. Technol., 42(12), 4364-4370.

Oh, S.Y., Chiu, P.C. and Cha, D.K. (2008), "Reductive transformation of 2,4,6-trinitrotoluene, hexahydro-1,3,5trinitro-1,3,5-triazine, and nitroglycerin by pyrite and magnetite", J. Hazard. Mater, 158(2-3), 652-665.

O'Loughlin, E.J. (2008), "Effects of electron transfer mediators on the bioreduction of lepidocrocite (gammaFeOOH) by Shewanella putrefaciens CN32", Environ. Sci. Technol., 42(18), 6876-6882.

Perez-Gonzalez, T., Jimenez-Lopez, C., Neal, A.L., Rull-perez, F., Rodriquez-Navarro, A., Fernandez-Vivas, A. and Ianez-Pareja E. (2010), "Magnetite biomineralization induced by Shewanella oneidensis", Geochim. Cosmochim. Acta, 74(3), 967-979.

Stookey, L.L. (1970), "Ferrozine-A new spectrophotometric reagent for iron" Anal. Chem., 42(7), 779-782.

Schmelling, D.C., Gray, K.A. and Kamat, P.V. (1996), "Role of reduction in the photocatalytic degradation of 
TNT", Environ. Sci. Technol., 30(8), 2547-2555.

Srinivasan, R., Lin, R., Spicer, R.L. and Davis, B.H. (1996), "Structural features in the formation of the green rust intermediate and ),-FeOOH", Colloid. Surface. A, 113(1-2), 97-105.

Spain, J.C., Hughes, J.B. and Knackmuss, H.J. (2000), Biodegradation of Nitroaromatic Compounds and Explosives, Lewis Publishers, New York, NY.

Sherburne, L.A., Shrout, J.D. and Alvarez, P.J.J. (2005), "Hexahydro-1,3,5-trinitro-1,3,5-triazine (RDX) degradation by Acetobacterium paludosum", Biodegradation, 16(6), 539-547.

Thompson, K.T., Crocker, F.H. and Fredrickson, H.L. (2005), "Mineralization of the cyclic nitramine explosive hexahydro-1,3,5-trinitro-1,3,5-triazine by Gordonia and Williamsia spp", Appl. Environ. Microb., 71(12), 82658272.

Yinon, J. (1990), Toxicity and Metabolism of Explosives, CRC Press, Boca Raton, FL.

Zachara, J.M., Fredrickson, J.K., Li, S.W., Kennedy, D.W., Smith, S.C. and Gassman, P.L. (1998), "Bacterial reduction of crystalline $\mathrm{Fe}(\mathrm{II})$ oxides in single phase suspensions and subsurface materials", Am. Mineral., 83(11-12), 1426-1443. 